\title{
Ability of Serum IgE Concentration to Predict Exacerbation Risk and Benralizumab Efficacy for Patients with Severe Eosinophilic Asthma
}

\author{
David J. Jackson · Marc Humbert · Ian Hirsch • Paul Newbold • \\ Esther Garcia Gil
}

Received: October 24, 2019 / Published online: December 14, 2019

(c) The Author(s) 2019

\begin{abstract}
Introduction: For patients with eosinophilic asthma with allergic characteristics, understanding the key drivers of exacerbations is important to identify optimal treatment strategies. Benralizumab is an interleukin-5 receptor alpha-directed cytolytic monoclonal antibody that significantly reduces exacerbation frequency for patients with severe, uncontrolled eosinophilic asthma. We evaluated the predictive value of baseline blood eosinophil counts vs. serum immunoglobulin E (IgE) concentrations
\end{abstract}

Enhanced Digital Features To view enhanced digital features for this article go to https://doi.org/10.6084/ m9.figshare.11211308.

Electronic Supplementary Material The online version of this article (https://doi.org/10.1007/s12325019-01191-2) contains supplementary material, which is available to authorized users.

D. J. Jackson ( $\square)$

Guy's Severe Asthma Centre, Guy's \& St Thomas'

NHS Trust, Great Maze Pond, London, UK

e-mail: David.Jackson@gstt.nhs.uk

D. J. Jackson

Asthma UK Centre, School of Immunology \&

Microbial Sciences, King's College London, Strand,

London, UK

M. Humbert

AP-HP, Service de Pneumologie, Hôpital Bicêtre, 78

Rue du Général Leclerc, Le Kremlin-Bicêtre, France on exacerbation risk and the association of these variables with benralizumab treatment effect.

Methods: Analyses were performed with data pooled from the phase III SIROCCO and CALIMA benralizumab trials. Crude annual asthma exacerbation rates (AERs) were determined for placebo as a function of baseline blood eosinophil counts and serum IgE concentrations with prespecified blood eosinophil count categories $(<150, \geq 150$ to $<300, \geq 300$ to $<450, \geq 450$ cells $/ \mu \mathrm{L}$ ) and $\operatorname{IgE}$ concentration quartiles $(<62.0, \geq 62.0$ to $<176.2, \geq 176.2$ to $<453.4$, and $\geq 453.4 \mathrm{kU} / \mathrm{L})$. We compared AERs for patients receiving benralizumab $30 \mathrm{mg}$ every 8 weeks (first three doses every 4 weeks) vs. placebo for overlapping baseline blood eosinophil count categories and serum IgE concentration quartiles via a regression approach and by continuously using locally weighted regression smoothing analysis.

I. Hirsch · P. Newbold

AstraZeneca, One MedImmune Way, Gaithersburg, MD, USA

E. Garcia Gil

AstraZeneca, Avgda. Diagonal, Barcelona, Spain 
Results: Exacerbation risk for patients with severe asthma receiving placebo increased with increasing baseline blood eosinophil counts but not with increasing serum IgE concentrations. Addition of baseline atopy status did not influence the relationship between IgE concentrations and exacerbation risk for patients receiving placebo. Patients with blood eosinophil counts $\geq 300$ cells $/ \mu \mathrm{L}$ had consistent decreases in exacerbation risk with benralizumab relative to placebo across all serum IgE concentration quartiles.

Conclusion: Baseline blood eosinophil counts, but not serum IgE concentrations, are an important predictor of exacerbation risk. Patients with severe eosinophilic asthma treated with benralizumab had consistent reductions in exacerbation risk, regardless of $\operatorname{IgE}$ concentrations.

Clinical Trial Registration: ClinicalTrials.gov: SIROCCO, NCT01928771; CALIMA, NCT01914757.

Keywords: Asthma; Benralizumab; CALIMA; Eosinophils; Exacerbations; Immunoglobulin $\mathrm{E}$; Interleukin-5 receptor; SIROCCO

\section{Key Summary Points}

Why carry out this study?

Patients with eosinophilic asthma can have elevated serum IgE concentrations

Eosinophilia is associated with asthma exacerbations, which can be reduced with benralizumab, an interleukin-5 receptor alpha-directed anti-eosinophil monoclonal antibody

We aimed to determine the importance of elevated blood eosinophil counts and serum IgE concentrations on exacerbation risk and their influence on benralizumab's ability to reduce exacerbation frequency for patients with eosinophilic asthma and a range of serum IgE concentrations

\section{What was learned from the study?}

Elevated blood eosinophil counts, but not serum IgE concentrations, are associated with increased exacerbation risk for patients with severe, uncontrolled asthma

Benralizumab reduces exacerbation risk for patients with elevated blood eosinophil counts regardless of serum $\operatorname{IgE}$ concentrations and, therefore, should be considered for patients with uncontrolled eosinophilic asthma with allergic characteristics

\section{PLAIN LANGUAGE SUMMARY}

Many patients with severe asthma have elevated numbers of eosinophils (a subset of white blood cells) and raised serum concentrations of immunoglobulin E (IgE; antibodies). Elevated eosinophil counts together with IgE concentrations are associated with more frequent asthma attacks. Benralizumab is a drug that almost completely depletes eosinophils and significantly reduces asthma attacks for patients with severe, uncontrolled asthma and elevated blood eosinophil counts. The individual influence of eosinophils and IgE on benralizumab efficacy has been published. In this study, we further extend the analyses to evaluate the interrelationship of eosinophil counts and IgE concentrations with asthma attack frequency and benralizumab efficacy for patients with severe, uncontrolled asthma. We evaluated the association of blood eosinophil counts and IgE concentrations with asthma attack frequency for patients with severe asthma who received highdosage inhaled corticosteroids plus additional controller medications but did not receive benralizumab in the benralizumab clinical trials. We observed that increased blood eosinophil counts were associated with greater asthma attack frequency, while serum IgE concentrations had no influence on asthma attack frequency. We also evaluated patients who 
received benralizumab and determined that benralizumab can reduce the occurrence of these attacks for patients with elevated blood eosinophil counts regardless of their serum IgE concentrations. Frequency of asthma attacks also decreased with benralizumab for patients with elevated serum IgE concentrations, but serum IgE concentrations did not influence benralizumab efficacy. Benralizumab is an efficacious treatment for patients with uncontrolled eosinophilic asthma, regardless of their IgE concentrations.

\section{INTRODUCTION}

Asthma is a heterogenous disease that affects more than 339 million people worldwide [1-3]. Allergic asthma is a common phenotype of asthma, and several factors such as elevated immunoglobulin E (IgE) concentrations and eosinophilia play an important role in the pathology of this disease [2-5]. A total of $47 \%$ of adults have both eosinophilic ( $>150$ cells $/ \mu \mathrm{L}$ ) and atopic asthma (with elevated IgE concentrations), while $78 \%$ of adults with atopic asthma also have eosinophilic asthma [5]. It is, therefore, important to identify the characteristics of individual patients with severe asthma to determine the optimal treatment regimen.

Omalizumab (Genentech, Inc., South San Francisco, CA, USA), a humanized anti-IgE monoclonal antibody, is approved as add-on therapy for patients aged 6 years or older with moderate to severe persistent, uncontrolled asthma with positive skin test or in vitro reactivity to a perennial aeroallergen [6]. In the phase III EXTRA clinical trial, omalizumab reduced exacerbation rates relative to placebo by $25 \%$ for patients with severe allergic asthma [7]. In a post hoc analysis of this study, patients with allergic asthma and blood eosinophil counts $\geq 260$ cells $/ \mu \mathrm{L}$ had a $32 \%$ reduction in asthma exacerbation rate with omalizumab relative to placebo, compared with a 9\% reduction for patients with blood eosinophil counts $<260$ cells $/ \mu \mathrm{L}$ [8]. Exacerbation rate reductions with omalizumab were similar regardless of serum IgE concentrations $[9,10]$.
Benralizumab (AstraZeneca, Cambridge, UK) is an interleukin-5 receptor alpha-directed cytolytic monoclonal antibody that induces direct, rapid, and nearly complete depletion of eosinophils via enhanced antibody-dependent cell-mediated cytotoxicity $[11,12]$. Benralizumab $30 \mathrm{mg}$ every 8 weeks (Q8W; first three doses every 4 weeks [Q4W]) is indicated for the add-on maintenance treatment of patients with severe asthma aged 12 years and older, and with an eosinophilic phenotype [13]. In the 48-week SIROCCO and 56-week CALIMA phase III studies, significant reductions in annual asthma exacerbation rates (AERs) by $51 \%(p<0.0001)$ and $28 \% \quad(p=0.0188)$, respectively, were achieved with benralizumab Q8W compared with placebo for patients with severe, uncontrolled asthma and baseline blood eosinophil counts $\geq 300$ cells $/ \mu \mathrm{L}[14,15]$. In addition, significant improvements were also achieved with benralizumab Q8W relative to placebo in prebronchodilator forced expiratory volume in $1 \mathrm{~s}$ $\left(\mathrm{FEV}_{1}\right) \quad(0.159 \mathrm{~L} \quad[p=0.0006]$ and $0.116 \mathrm{~L}$ $[p=0.0102]$, respectively) at the end of treatment (EOT) $[14,15]$.

Benralizumab Q8W has also been demonstrated to reduce exacerbations and improve lung function for patients with severe, uncontrolled asthma with blood eosinophil counts $\geq 300$ cells $/ \mu \mathrm{L}$ and with either high serum IgE concentrations ( $\geq 150 \mathrm{kU} / \mathrm{L} ; 53 \%$ of patients) or low serum IgE concentrations $(<150 \mathrm{kU} / \mathrm{L} ; 47 \%$ of patients), with or without atopy (based on Phadiatop [Phadia AB/Thermo Fisher Scientific, Uppsala, Sweden] test results), or for those who met the criteria similar to patients who might qualify for omalizumab treatment (serum IgE concentrations $30-700 \mathrm{kU} / \mathrm{L}$ and with atopy) or those who did not meet these criteria [16]. AERs decreased by $42 \%$ (high serum IgE concentrations; $p<0.0001$ ), 43\% (low serum IgE concentrations; $p=0.0004$ ), $40 \%$ (with atopy; $p<0.0001$ ), 46\% (without atopy; $p=0.0001$ ), $46 \%$ (met criteria; $p=0.0002$ ), and 39\% (did not meet criteria; $p<0.0001$ ) with benralizumab Q8W relative to placebo [16].

However, this dichotomous analysis has limitations, as it does not allow evaluation of differences in treatment effects across the full range of IgE concentrations. Unlike with blood 
eosinophil counts, there is lack of consensus on an IgE cut-off value that defines high vs. low concentrations. To address this and determine benralizumab efficacy for patients across a range of IgE concentrations, including very high, we categorized the study population into quartiles, an approach used to assess the effect of omalizumab on exacerbations [10]. We analyzed pooled data from the SIROCCO and CALIMA studies to determine the influence of baseline blood eosinophil counts and serum IgE, across a range of concentrations, on exacerbation risk for patients with severe, uncontrolled asthma. Furthermore, as the influences of baseline blood eosinophil counts and serum IgE concentrations on exacerbation risk and benralizumab efficacy were previously studied independently, although variable concentrations of these biomarkers coexist for patients, we evaluated these two biomarkers together. We aimed to assess the potential utility of benralizumab for patients with eosinophilic asthma with allergic characteristics.

\section{METHODS}

\section{Study Design and Participants}

SIROCCO and CALIMA were randomized, double-blind, parallel-group, placebo-controlled, international, phase III studies [14, 15]. The study designs consisted of an enrollment visit (week-4), a 4-week screening and run-in phase, randomization (week 0 ), treatment period from weeks 0 to 48 (SIROCCO) or 56 (CALIMA), and a final follow-up visit 8 weeks (SIROCCO) or 4 weeks (CALIMA) after the EOT period.

Enrollment criteria for the studies have been published [14, 15]. Male and female patients 12-75 years of age, weighing at least $40 \mathrm{~kg}$, and with physician-diagnosed asthma that required treatment with medium- to high-dosage inhaled corticosteroids (ICS) and long-acting $\beta_{2^{-}}$ agonists (LABA) for at least 12 months before enrollment were included. Patients had two or more asthma exacerbations within 12 months before the date of enrollment that required systemic corticosteroid therapy or a temporary increase in usual maintenance oral corticosteroid dosages $[14,15]$. Before any patients enrolled, an independent ethics committee or institutional review board at each study center approved the clinical study protocol, and the national regulatory authority either approved the clinical study protocol or received a notification according to local regulations (see electronic supplementary materials). Studies were conducted in accordance with the Declaration of Helsinki, the International Conference on Harmonisation of Technical Requirements for Registration of Pharmaceuticals for Human Use and Good Clinical Practice guidelines, and the ethics committee at each participating site $[14,15]$. All patients provided written informed consent at enrollment.

\section{Treatments}

In SIROCCO and CALIMA, patients were randomized 1:1:1 to receive placebo $\mathrm{Q} 4 \mathrm{~W}$, benralizumab $30 \mathrm{mg}$ subcutaneously Q4W, or benralizumab $30 \mathrm{mg}$ subcutaneously Q8W (first three doses Q4W). Patients with baseline blood eosinophil counts $\geq 300$ cells/ $\mu \mathrm{L}$ and $<300$ cells/ $\mu \mathrm{L}$ were recruited at a ratio of approximately $2: 1$, respectively.

\section{Outcomes}

In the present study, we performed analyses for patients who received placebo or the indicated benralizumab dosage (30 $\mathrm{mg} \mathrm{Q} 8 \mathrm{~W})$ in addition to high-dosage ICS and LABA (defined as fluticasone propionate $\geq 500 \mathrm{mg} /$ day or equivalent total daily dosage) pooled from the SIROCCO and CALIMA studies.

AERs were determined as a function of baseline blood eosinophil counts or serum IgE concentrations, either separately or combined. An exacerbation was defined as asthma worsening that led to either systemic corticosteroid use (or temporary increase in a stable oral corticosteroid background dosage) for at least 3 days or a single depot-injectable dose of corticosteroid; an asthma-related emergency department or urgent care visit (duration $<24 \mathrm{~h}$ ) that required systemic corticosteroid use; or an asthma-related inpatient hospital 
admission (duration $\geq 24 \mathrm{~h}$ ). Asthma worsening was defined as any new or increased symptoms or signs that were concerning to the patient or related to an asthma daily diary alert $[14,15]$.

Baseline blood eosinophil counts were evaluated as a continuous function, by categories prespecified in the SIROCCO and CALIMA studies $(<150, \geq 150$ to $<300, \geq 300$ to $<450$, and $\geq 450$ cells $/ \mu \mathrm{L}$ ) and also for the SIROCCO and CALIMA primary population ( $\geq 300$ cells/ $\mu \mathrm{L})$. Baseline serum IgE concentrations were evaluated as a continuous function or by quartiles $(<62.0, \geq 62.0$ to $<176.2, \geq 176.2$ to $<453.4$, and $\geq 453.4 \mathrm{kU} / \mathrm{L})$. Evaluation of AERs as a function of serum IgE concentrations was also determined on the basis of baseline atopy status. Atopy was defined as a positive Phadiatop test reaction. The Phadiatop test is a multiallergen inhalant screening blood test with extracts for house dust mites, cat and dog dander, mold spores, and tree, grass, and weed pollen.

\section{Statistical Analysis}

This analysis was performed for the full analysis set according to the intention-to-treat principle for the pooled SIROCCO and CALIMA studies. The full analysis set included all randomized patients who received any study treatment, regardless of their protocol adherence and continued participation in the study. The similarity of the SIROCCO and CALIMA studies allowed for their results to be pooled [14, 15]. Similarities included study design (the only difference being treatment period: 48 weeks for SIROCCO and 56 weeks for CALIMA), inclusion and exclusion criteria (except CALIMA included patients who used medium-dosage ICS), treatment, randomization, stratification, and outcomes. Included patients had similar baseline clinical characteristics across the trials. This permitted us to obtain more accurate estimates of the relationship of baseline blood eosinophil counts and serum IgE concentrations with AERs, both for placebo and for benralizumab relative to placebo. Analyses were performed with SAS 9.4 (SAS Institute, Cary, NC, USA).
We used locally weighted regression smoothing analysis with corresponding confidence intervals (CIs) to determine the relationship between AERs with blood eosinophil counts and serum IgE concentrations. We analyzed AERs and corresponding ratios via a negative binomial model, with adjustments for study, treatment, region, prior exacerbations, and oral corticosteroid use at time of randomization. The log of each patient's corresponding follow-up time was used as an offset variable in the model to adjust for different exposure times during which the events occurred. We determined the estimated treatment effect (i.e., rate ratio of benralizumab vs. placebo), corresponding $\mathrm{CI}$, and two-sided $p$ value for the rate ratio.

\section{RESULTS}

Demographics and baseline clinical characteristics of SIROCCO and CALIMA patients were, in general, balanced between treatment groups overall [14-16].

There was a positive relationship between baseline blood eosinophil counts and AERs for patients in the placebo arm (with background high-dosage ICS/LABA) (Fig. 1). However, there was no relationship between increasing baseline serum IgE concentrations and AERs (Fig. 2). Baseline atopy status did not influence the relationship between baseline serum IgE concentrations and AERs (Fig. 3). Benralizumab reduced AERs for each of these patient populations, with greater benralizumab response with increasing blood eosinophil counts and consistent improvements with increasing serum IgE concentrations (Figs. 1, 2, 3).

When we evaluated the relationship between blood eosinophil counts and serum IgE concentrations in combination, greater baseline blood eosinophil counts (i.e., $\geq 450$ cells $/ \mu \mathrm{L}$ ) were associated with larger AERs than lesser baseline blood eosinophil counts (i.e., $<150$ cells $/ \mu \mathrm{L}$ ), regardless of baseline serum IgE concentrations (Table 1) for patients receiving placebo. AERs increased with increasing baseline blood eosinophil count categories for most serum IgE concentration quartiles, although there was some variability. AERs were not 


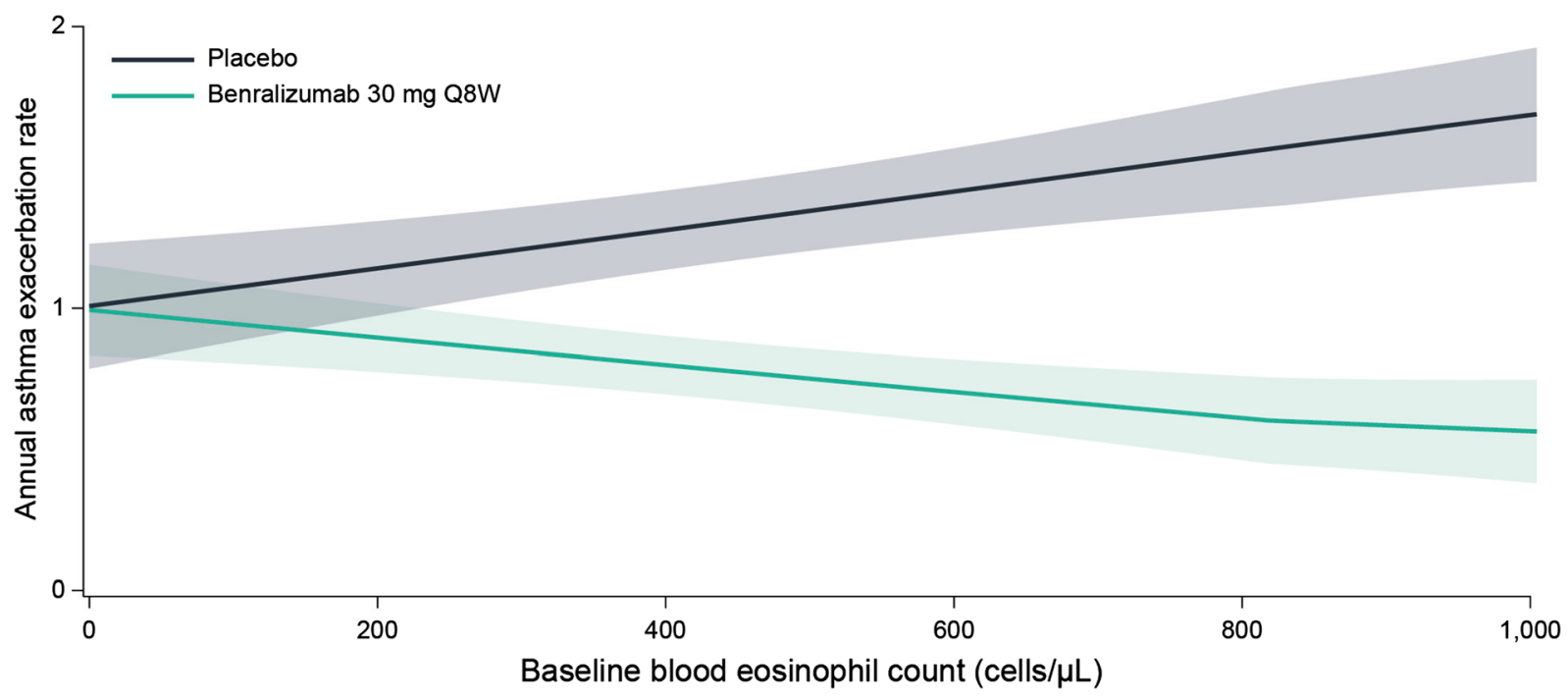

Fig. 1 LOESS plot analysis of association between baseline blood eosinophil counts and exacerbation frequency (full analysis set). CI confidence interval, LOESS locally estimated scatterplot smoothing, $Q 8 W$ every 8 weeks (first three doses every 4 weeks). Shaded areas represent 95\% CI. Baseline blood eosinophil counts $>1000$ cells $/ \mu \mathrm{L}$ are included in the model but not presented in the figure

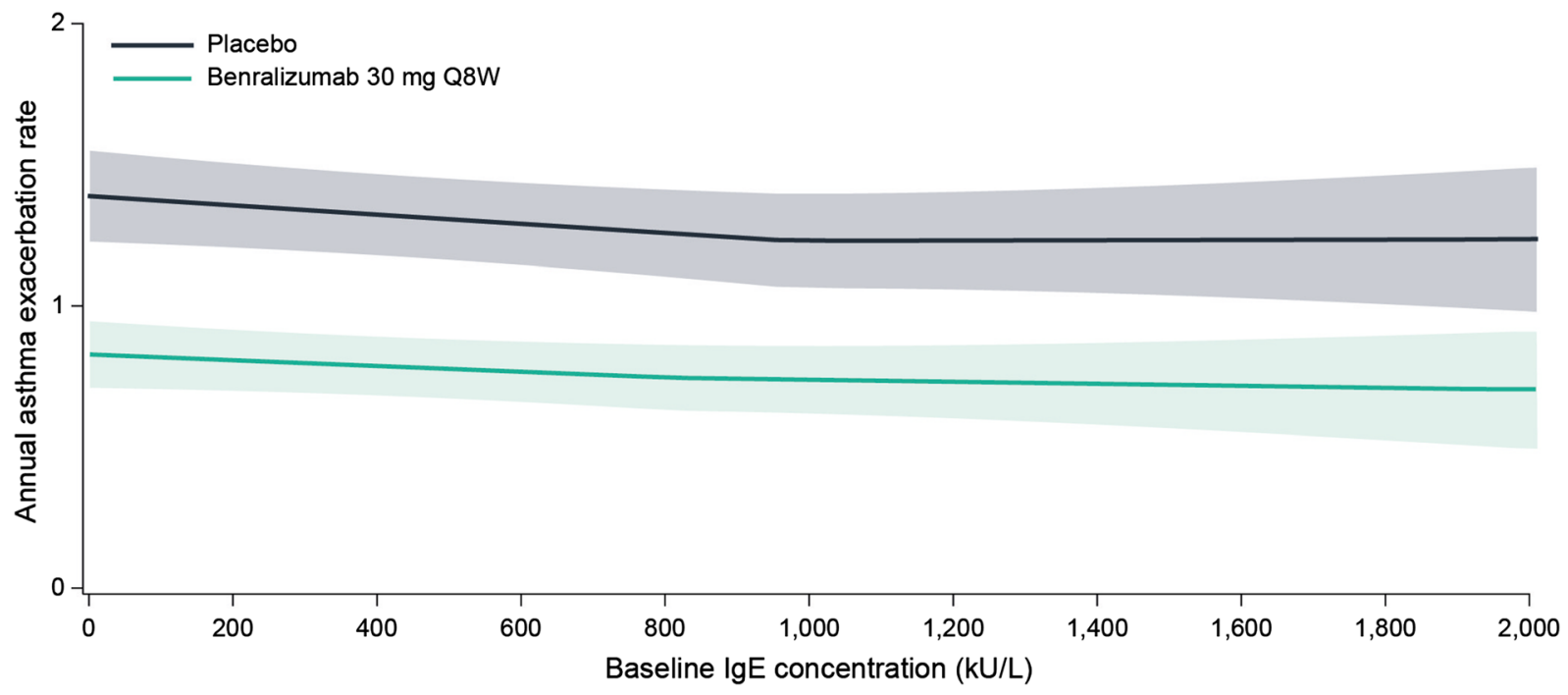

Fig. 2 LOESS plot analysis of association between baseline serum $\operatorname{IgE}$ concentrations and exacerbation frequency (full analysis set). CI confidence interval, $I g E$ immunoglobulin E, LOESS locally estimated scatterplot smoothing,

greater in the fourth quartile of baseline serum IgE concentrations compared with the first quartile, and no obvious pattern in AER changes was observed with increasing baseline IgE concentrations across baseline blood eosinophil count categories.
Q $8 W$ every 8 weeks (first three doses every 4 weeks). Shaded areas represent 95\% CI. IgE concentrations $>2000 \mathrm{kU} / \mathrm{L}$ are included in the model but not presented in the figure

Patients with eosinophilic asthma ( $\geq 300$ cells $/ \mu \mathrm{L}$ ) treated with benralizumab had consistent decreases in AER relative to placebo regardless of baseline serum IgE concentration quartiles (Table 2, Fig. 4). Rate ratios ranged from 0.47 (95\% CI $0.31,0.72 ; p=0.0004)$ to 

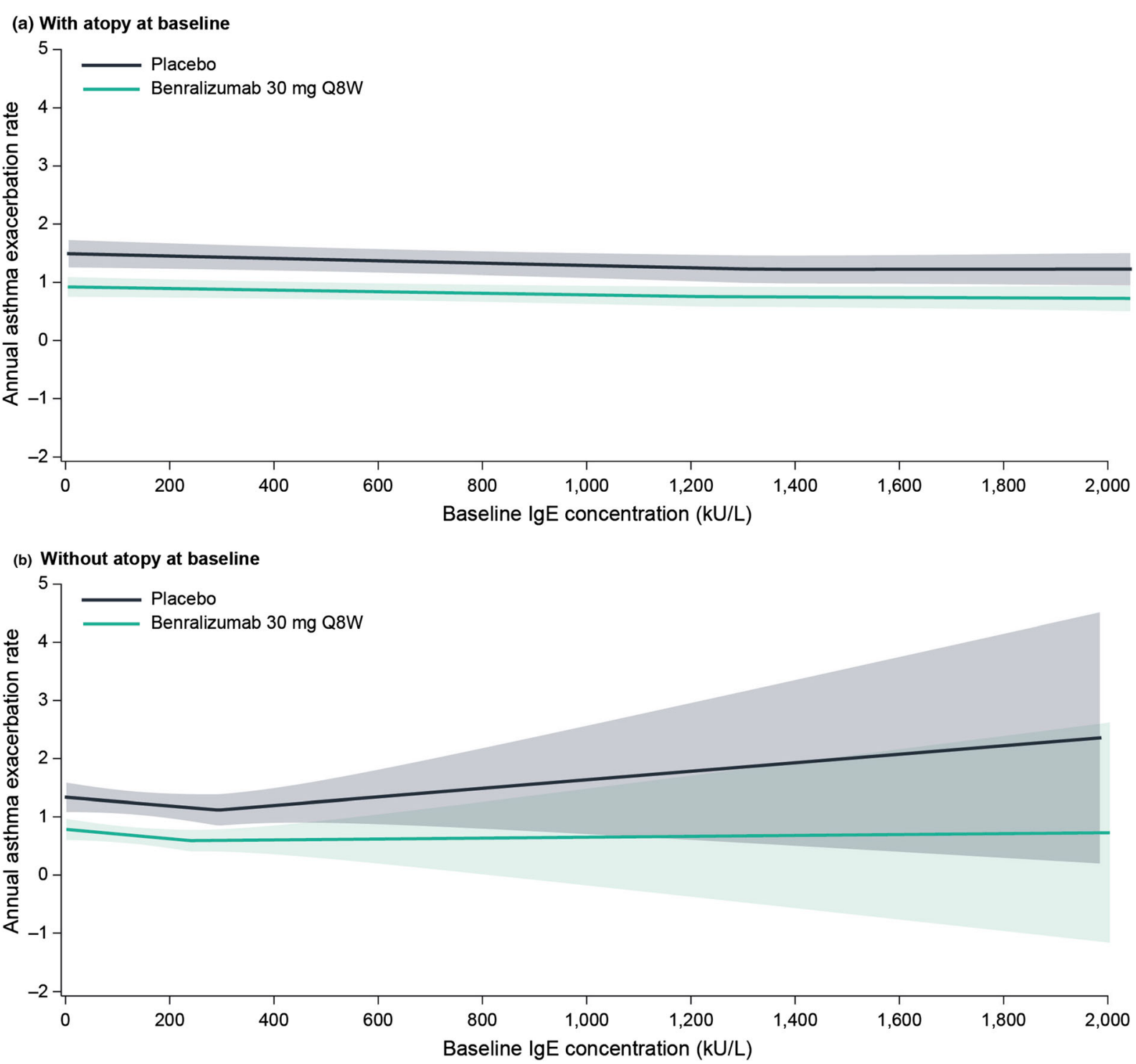

Fig. 3 LOESS plot analysis of association of baseline serum IgE concentrations and atopy status with exacerbation frequency (full analysis set). CI confidence interval, $I g E$ immunoglobulin E, LOESS locally estimated

$0.56(95 \%$ CI 0.37, 0.84; $p=0.0057)$ across baseline serum $\operatorname{IgE}$ concentration quartiles (Table 2).

\section{DISCUSSION}

IgE and eosinophils play distinct roles in the pathogenesis of allergic asthma [4, 17], scatterplot smoothing, $Q 8 W$ every 8 weeks (first three doses every 4 weeks). Shaded areas represent 95\% CI. IgE concentrations $>2000 \mathrm{kU} / \mathrm{L}$ are included in the model but not presented in the figure

although there is probably some overlap in these mechanisms because cross-linking of $\operatorname{IgE}$ also leads to increased eosinophil counts. IgE is associated with the acute and chronic phases of the disease. In the acute phase, allergens stimulate the production of IgE, and cross-linking of IgE promotes the inflammatory cascade associated with development of allergic asthma, leading to a significant increase in eosinophil 
Table 1 Effect of baseline blood eosinophil counts and serum IgE concentrations on annual asthma exacerbation rates for patients receiving placebo (full analysis set)

\begin{tabular}{lllll}
\hline Serum IgE concentration $(\mathbf{k U} / \mathbf{L})$ & \multicolumn{4}{l}{ Crude AER } \\
\cline { 2 - 5 } & \multicolumn{4}{l}{ Baseline blood eosinophil count $($ cells $/ \boldsymbol{\mu L})$} \\
\cline { 2 - 5 } & $<\mathbf{1 5 0}$ & $\mathbf{1 5 0}$ to $<\mathbf{3 0 0}$ & $\mathbf{2 3 0 0}$ to $<\mathbf{4 5 0}$ & $\mathbf{2 4 5 0}$ \\
\hline$<62.0$ & $1.25(n=53)$ & $0.91(n=57)$ & $1.28(n=32)$ & $1.44(n=43)$ \\
$\geq 62.0$ to $<176.2$ & $1.57(n=34)$ & $0.94(n=45)$ & $1.15(n=46)$ & $1.84(n=66)$ \\
$\geq 176.2$ to $<453.4$ & $1.10(n=30)$ & $1.93(n=42)$ & $1.19(n=45)$ & $1.38(n=80)$ \\
$\geq 453.4$ & $0.80(n=29)$ & $0.84(n=31)$ & $1.10(n=39)$ & $1.33(n=90)$ \\
\hline
\end{tabular}

$A E R$ annual asthma exacerbation rate, $I g E$ immunoglobulin $\mathrm{E}$

counts in the chronic phase of the disease $[4,17]$. The relevance of each component in the development and progression of allergic asthma symptoms, such as exacerbation frequency and reduced lung function, is unclear and may likely be different for each patient.

In this study, we evaluated the influence of baseline blood eosinophil counts and serum IgE concentrations on exacerbation frequency with a data set pooled from the phase III SIROCCO and CALIMA trials for benralizumab. While increasing baseline blood eosinophil counts were directly associated with greater AERs for patients receiving placebo at the end of the studies, baseline serum IgE concentrations had no influence on AERs. These results suggest that treatments that decrease eosinophils may reduce exacerbation frequency for patients with eosinophilic asthma with allergic characteristics, regardless of serum IgE concentrations. This conclusion was supported by our findings that benralizumab treatment resulted in substantial reductions in exacerbation rates for patients with severe, uncontrolled eosinophilic asthma regardless of serum IgE concentrations. These results expand on earlier findings that patients with blood eosinophil counts $\geq 300$ cells $/ \mu \mathrm{L}$ with either serum IgE concentrations $\geq 150$ or $<150 \mathrm{kU} / \mathrm{L}$, with or without atopy, or who might or might not qualify for omalizumab treatment had substantial reductions ( $\geq 40 \%)$ in exacerbation frequencies [16].

Omalizumab is an approved add-on treatment for patients with moderate to severe, uncontrolled allergic asthma with elevated serum IgE concentrations [18]. Similar to findings for omalizumab [9], baseline serum $\operatorname{IgE}$ concentrations do not predict benralizumab response. However, unlike omalizumab [7, 9], increasing baseline blood eosinophil counts are clearly associated with greater benralizumab efficacy. Overall, these studies suggest that omalizumab treatment may be efficacious for reducing symptoms of allergic asthma that are stimulated by the cross-linking of specific IgE in response to an allergic trigger. For patients with eosinophilic asthma with allergic characteristics, alternative treatments, such as benralizumab, may be needed.

Mepolizumab, a marketed human antiinterleukin-5 monoclonal antibody for patients with severe eosinophilic asthma [19], has been evaluated in two separate studies for patients who either received [20] or were qualified at study entry [21] to receive omalizumab treatment. In a post hoc analysis of the phase III MENSA trial [22], patients who received omalizumab had a $57 \%$ exacerbation rate reduction with mepolizumab vs. placebo (compared with $47 \%$ for those who did not receive omalizumab) [20]. In a post hoc meta-analysis of data from the phase III MENSA [22] and MUSCA [23] trials, mepolizumab reduced exacerbation rates vs. placebo by $57 \%$ and $55 \%$ for patients who were qualified or unqualified for omalizumab (based on prescribing and dosing criteria), respectively [21]. Together with our findings, this supports the use of agents that target eosinophils directly 
Table 2 Annual asthma exacerbation rate reductions with benralizumab vs. placebo based on baseline serum IgE concentrations (full analysis set; baseline blood eosinophil counts $\geq 300$ cells $/ \mu \mathrm{L}$ )

\begin{tabular}{|c|c|c|}
\hline Serum IgE concentration $(\mathbf{k U} / \mathrm{L})$ & Placebo & Benralizumab Q8W \\
\hline \multicolumn{3}{|l|}{$<62.0$} \\
\hline Number of patients analyzed & 75 & 73 \\
\hline Rate estimate $(95 \% \mathrm{CI})$ & $1.40(1.00,1.96)$ & $0.71(0.46,1.09)$ \\
\hline Absolute difference estimate vs. placebo ( $95 \% \mathrm{CI}$ ) & - & $-0.69(-1.21,-0.17)$ \\
\hline Rate ratio vs. placebo (95\% CI) & - & $0.51(0.31,0.84)$ \\
\hline Nominal $p$ vs. placebo & - & 0.0079 \\
\hline \multicolumn{3}{|l|}{$\geq 62.0$ to $<176.2$} \\
\hline Number of patients analyzed & 112 & 109 \\
\hline Rate estimate $(95 \% \mathrm{CI})$ & $1.66(1.26,2.18)$ & $0.79(0.56,1.10)$ \\
\hline Absolute difference estimate vs. placebo (95\% CI) & - & $-0.87(-1.38,-0.37)$ \\
\hline Rate ratio vs. placebo $(95 \% \mathrm{CI})$ & - & $0.47(0.31,0.72)$ \\
\hline Nominal $p$ vs. placebo & - & 0.0004 \\
\hline \multicolumn{3}{|l|}{$\geq 176.2$ to $<453.4$} \\
\hline Number of patients analyzed & 125 & 106 \\
\hline Rate estimate $(95 \% \mathrm{CI})$ & $1.37(1.07,1.76)$ & $0.71(0.52,0.97)$ \\
\hline Absolute difference estimate vs. placebo (95\% CI) & - & $-0.67(-1.06,-0.27)$ \\
\hline Rate ratio vs. placebo $(95 \% \mathrm{CI})$ & - & $0.52(0.35,0.76)$ \\
\hline Nominal $p$ vs. placebo & - & 0.0008 \\
\hline \multicolumn{3}{|l|}{$\geq 453.4$} \\
\hline Number of patients analyzed & 129 & 128 \\
\hline Rate estimate $(95 \% \mathrm{CI})$ & $1.22(0.92,1.62)$ & $0.68(0.48,0.96)$ \\
\hline Absolute difference estimate vs. placebo ( $95 \%$ CI) & - & $-0.54(-0.93,-0.15)$ \\
\hline Rate ratio vs. placebo (95\% CI) & - & $0.56(0.37,0.84)$ \\
\hline Nominal $p$ vs. placebo & - & 0.0057 \\
\hline
\end{tabular}

Estimates were calculated via a negative binomial model, with adjustments for study, treatment, region, prior exacerbations, and oral corticosteroid use at time of randomization. The log of each patient's corresponding follow-up time was used as an offset variable in the model to adjust for different exposure times during which the events occurred $C I$ confidence interval, IgE immunoglobulin E, $Q 8 W$ every 8 weeks (first three doses every 4 weeks)

(benralizumab) or indirectly (mepolizumab) to reduce eosinophils for the treatment of patients with eosinophilic asthma with allergic characteristics.

A limitation of this study was the small numbers of patients for the different subgroups, which restricted interpretation of the findings with no consistent trends. Another limitation was that this post hoc analysis was not part of the general testing strategy. Because of this, all comparator results of benralizumab vs. placebo use nominal $p$ values, and no formal statistical 


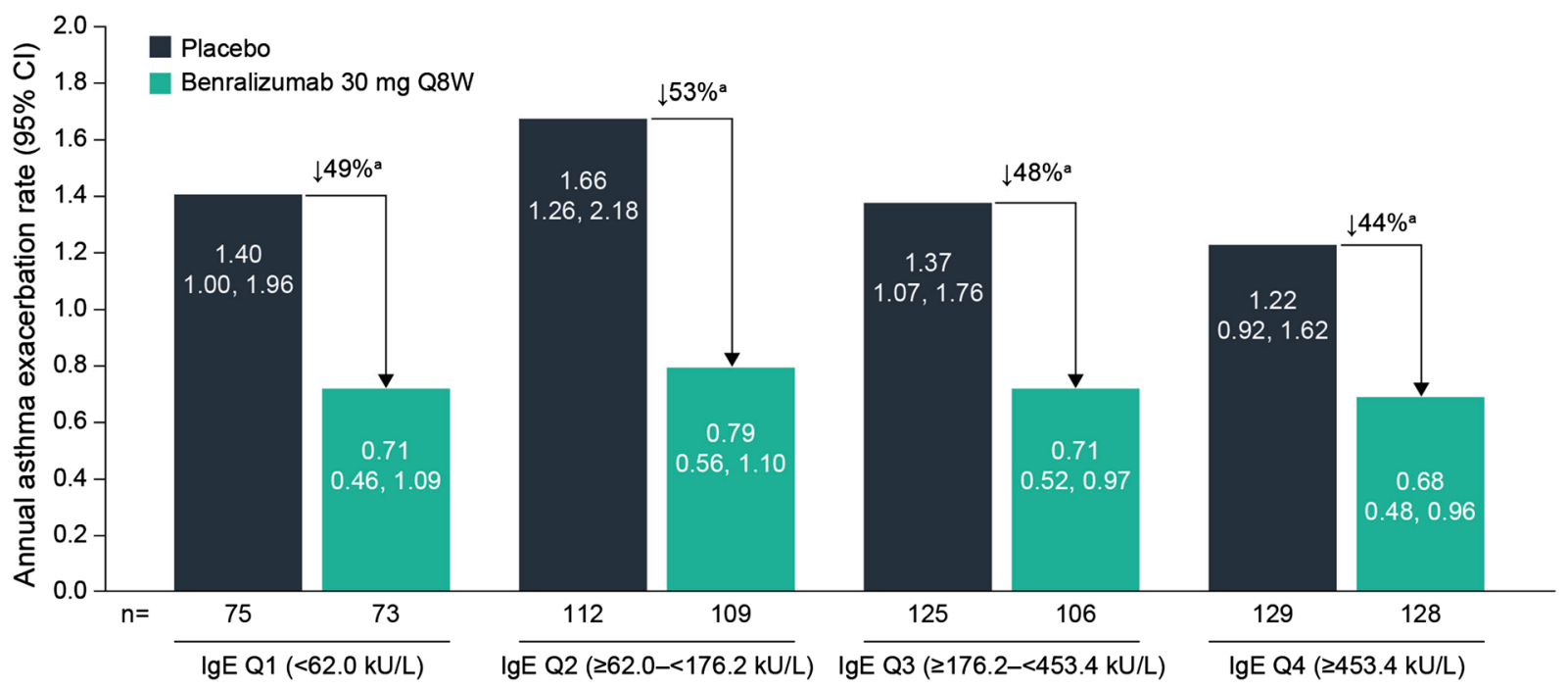

Fig. 4 Effect of baseline serum IgE concentrations on annual asthma exacerbation rate reduction with benralizumab vs. placebo (full analysis set; baseline blood eosinophil counts $\geq 300$ cells $/ \mu \mathrm{L}$ ). CI confidence interval, IgE immunoglobulin E, Q quartile, Q8W every 8 weeks (first three doses every 4 weeks). Estimates were calculated

significance can be inferred. Lastly, this study was not performed for patients who were diagnosed with allergic asthma, and any association of improvements with benralizumab for this patient population is speculative.

\section{CONCLUSIONS}

Blood eosinophil counts, but not serum $\operatorname{IgE}$ concentration, predict exacerbation risk. Exacerbation rate reductions with benralizumab for patients with eosinophilia and elevated serum IgE concentrations and/or atopy indicate a potential benefit of benralizumab for patients with eosinophilic asthma with allergic characteristics. Physicians should consider eosinophildepleting therapies for patients with uncontrolled asthma and elevated blood eosinophil counts, regardless of serum IgE concentrations.

\section{ACKNOWLEDGEMENTS}

We thank the patients who participated in the SIROCCO and CALIMA studies. via a negative binomial model, with adjustments for study, treatment, region, prior exacerbations, and oral corticosteroid use at time of randomization. The log of each patient's corresponding follow-up time was used as an offset variable in the model to adjust for different exposure times during which the events occurred. ${ }^{\mathrm{a}} p<0.01$

Funding. AstraZeneca (Cambridge, UK) funded this study and the journal's Rapid Service Fee and Open Access publication. All authors had full access to all of the data in this study and take complete responsibility for the integrity of the data and accuracy of the data analysis.

Authorship. All named authors meet the International Committee of Medical Journal Editors (ICMJE) criteria for authorship for this article, take responsibility for the integrity of the work as a whole, and have given their approvals for this version to be published.

Authorship Contributions. All authors conceived and designed the study. Ian Hirsch, Paul Newbold, and Esther Garcia Gil acquired the data. All authors analyzed and interpreted the data. All authors participated in the development and review of the manuscript and gave the approval to submit for publication.

Medical Writing, Editorial, and Other Assistance. Writing and editing support, including preparation of the draft manuscript 
under the direction and guidance of the authors, incorporation of author feedback, and manuscript submission, was provided by Alan Saltzman, PhD, CMPP (JK Associates, Inc., Conshohocken, PA, USA), and Michael A. Nissen, ELS (AstraZeneca, Gaithersburg, MD, USA). This support was funded by AstraZeneca.

Disclosures. David J. Jackson reports personal fees from AstraZeneca, Chiesi Pharmaceuticals, GlaxoSmithKline, and Napp Pharmaceuticals, and nonfinancial support from Boehringer Ingelheim and Teva Pharmaceuticals, outside the submitted work. Marc Humbert reports personal fees from Actelion, Merck, and United Therapeutics, and grants and personal fees from Bayer and GlaxoSmithKline, outside the submitted work. Ian Hirsch is an employee of AstraZeneca. Paul Newbold is an employee of AstraZeneca. Esther Garcia Gil is an employee of AstraZeneca.

Compliance with Ethics Guidelines. Before any patients enrolled, an independent ethics committee or institutional review board at each study center approved the clinical study proto$\mathrm{col}$, and the national regulatory authority either approved the clinical study protocol or received a notification according to local regulations (see electronic supplementary materials). Studies were conducted in accordance with the Declaration of Helsinki, the International Conference on Harmonisation of Technical Requirements for Registration of Pharmaceuticals for Human Use and Good Clinical Practice guidelines, and the ethics committee at each participating site. All patients provided written informed consent at enrollment.

Data Availability. Data underlying the findings described in this manuscript may be requested in accordance with AstraZeneca's data-sharing policy described at https:// astrazenecagroup-dt.pharmacm.com/DT/Home.

Open Access. This article is licensed under a Creative Commons Attribution-NonCommercial 4.0 International License, which permits any non-commercial use, sharing, adaptation, distribution and reproduction in any medium or format, as long as you give appropriate credit to the original author(s) and the source, provide a link to the Creative Commons licence, and indicate if changes were made. The images or other third party material in this article are included in the article's Creative Commons licence, unless indicated otherwise in a credit line to the material. If material is not included in the article's Creative Commons licence and your intended use is not permitted by statutory regulation or exceeds the permitted use, you will need to obtain permission directly from the copyright holder. To view a copy of this licence, visit http://creativecommons.org/licenses/by$\mathrm{nc} / 4.0 /$.

\section{REFERENCES}

1. Global Asthma Network. The global asthma report. 2018. http://www.globalasthmareport.org/Global\% 20Asthma\%20Report\%202018.pdf. Accessed 9 Dec 2019.

2. Wenzel S. Severe asthma: from characteristics to phenotypes to endotypes. Clin Exp Allergy. 2012;42:650-8.

3. Chung KF, Wenzel SE, Brozek JL, et al. International ERS/ATS guidelines on definition, evaluation and treatment of severe asthma. Eur Respir J. 2014;43: 343-73.

4. Matucci A, Vultaggio A, Maggi E, Kasujee I. Is IgE or eosinophils the key player in allergic asthma pathogenesis? Are we asking the right question? Respir Res. 2018;19:113.

5. Tran TN, Zeiger RS, Peters SP, et al. Overlap of atopic, eosinophilic, and TH2-high asthma phenotypes in a general population with current asthma. Ann Allergy Asthma Immunol. 2016;116:37-42.

6. Xolair [US prescribing information]. Genentech, Inc. 2019. https://www.gene.com/download/pdf/ xolair_prescribing.pdf. Accessed 27 Aug 2019.

7. Hanania NA, Alpan O, Hamilos DL, et al. Omalizumab in severe allergic asthma inadequately controlled with standard therapy: a randomized trial. Ann Intern Med. 2011;154:573-82.

8. Hanania NA, Wenzel S, Rosen $\mathrm{K}$, et al. Exploring the effects of omalizumab in allergic asthma: an analysis of biomarkers in the EXTRA study. Am J Respir Crit Care Med. 2013;187:804-11. 
9. Humbert M, Taille C, Mala L, et al. Omalizumab effectiveness in patients with severe allergic asthma according to blood eosinophil count: the STELLAIR study. Eur Respir J. 2018;51:1702523.

10. Bousquet J, Rabe K, Humbert M, et al. Predicting and evaluating response to omalizumab in patients with severe allergic asthma. Respir Med. 2007;101: 1483-92.

11. Kolbeck R, Kozhich A, Koike M, et al. MEDI-563, a humanized anti-IL-5 receptor alpha mAb with enhanced antibody-dependent cell-mediated cytotoxicity function. J Allergy Clin Immunol. 2010;125:1344-53.

12. Pham TH, Damera G, Newbold P, Ranade K. Reductions in eosinophil biomarkers by benralizumab in patients with asthma. Respir Med. 2016;111:21-9.

13. Fasenra [US prescribing information]. AstraZeneca Pharmaceuticals LP. 2017. https://www.azpicentral. com/fasenra/fasenra.pdf\#page $=1$. Accessed 27 Aug 2019.

14. Bleecker ER, FitzGerald JM, Chanez P, et al. Efficacy and safety of benralizumab for patients with severe asthma uncontrolled with high-dosage inhaled corticosteroids and long-acting beta2-agonists (SIROCCO): a randomised, multicentre, placebocontrolled phase 3 trial. Lancet. 2016;388:2115-27.

15. FitzGerald JM, Bleecker ER, Nair P, et al. Benralizumab, an anti-interleukin-5 receptor alpha monoclonal antibody, as add-on treatment for patients with severe, uncontrolled, eosinophilic asthma (CALIMA): a randomised, double-blind, placebocontrolled phase 3 trial. Lancet. 2016;388:2128-41.

16. Chipps BE, Newbold P, Hirsch I, Trudo F, Goldman M. Benralizumab efficacy by atopy status and serum immunoglobulin E for patients with severe, uncontrolled asthma. Ann Allergy Asthma Immunol. 2018;120:504-11.

17. Froidure A, Mouthuy J, Durham SR, Chanez P, Sibille Y, Pilette C. Asthma phenotypes and IgE responses. Eur Respir J. 2016;47:304-19.

18. Global Initiative for Asthma. Global strategy for asthma management and prevention. 2019. https:// ginasthma.org/wp-content/uploads/2019/06/ GINA-2019-main-report-June-2019-wms.pdf. Accessed 28 Aug 2019.

19. Nucala [US prescribing information]. GlaxoSmithKline LLC. 2019. https://gsksource. com/pharma/content/dam/GlaxoSmithKline/US/ en/Prescribing_Information/Nucala/pdf/NUCALAPI-PIL-IFU-COMBINED.PDF. Accessed 27 Aug 2019.

20. Magnan A, Bourdin A, Prazma CM, et al. Treatment response with mepolizumab in severe eosinophilic asthma patients with previous omalizumab treatment. Allergy. 2016;71:1335-44.

21. Humbert M, Albers FC, Bratton DJ, et al. Effect of mepolizumab in severe eosinophilic asthma according to omalizumab eligibility. Respir Med. 2019;154:69-75.

22. Ortega HG, Liu MC, Pavord ID, et al. Mepolizumab treatment in patients with severe eosinophilic asthma. N Engl J Med. 2014;371:1198-207.

23. Chupp GL, Bradford ES, Albers FC, et al. Efficacy of mepolizumab add-on therapy on health-related quality of life and markers of asthma control in severe eosinophilic asthma (MUSCA): a randomised, double-blind, placebo-controlled, parallel-group, multicentre, phase $3 \mathrm{~b}$ trial. Lancet Respir Med. 2017;5:390-400. 